actuelle la plus probable est celle d'une "transposition" du gène codant pour la protéine de la cuticule dans le locus Gart, créant ainsi un intron nouveau contenant ce gène. Les phénomènes de "transposition ", c'est-à-dire de changement de position de fragments d'ADN transposés d'un site à un autre site du génome, sont d'ailleurs bien connus dans de très nombreuses espèces, notamment les drosophiles.

Une dernière question concerne la fréquence réelle de phénomènes similaires à ceux rapportés ici. Il existe certes d'autres exemples d'introns pouvant coder pour des protéines, principalement au niveau des gènes mitochondriaux de champignons (notamment de levures) et de chloroplastes de plantes. Dans ces cas, cependant, la séquence codante intronique est située sur le même brin que celles des exons du gène dans lequel elle est située, et sa transcription est colinéaire avec celle de ce gène. Les protéines introniques correspondantes pourraient intervenir dans l'épissage [2] ou la transposition [3] de ces introns. L'article commenté ici rapporte donc bien le premier exemple de l'intrication de deux gènes totalement différents dont les contrôles de transcription sont indépendants. Il n'est cependant pas sûr que l'on ait systématiquement recherché des séquences potentiellement codantes sur les deux brins d'introns dont certains sont immenses (jusqu'à $60 \mathrm{~kb}$ !) et pourraient bien contenir maintes informations ignorées jusqu'à présent. Nul doute que des dizaines de laboratoires dans le monde ne se soient d'ores et déjà mis à vérifier ce point grâce à leurs ordinateurs; la réponse est donc probablement pour bientôt. A. K.

I. Henikoff S, Keene MA, Fechtel K, Fristom JW. Gene within a gene:nested drosophila genes encode unrelated proteins on opposite DNA strands. Cell 1986; $44: 33-42$.

2. Lazowska J, Jacq C, Slonimski, P.P. Sequence of introns and flanking exons in wild type and box 3 mutants of cytochrome b, reveals an interlaced splicing protein coded by an intron. Cell 1980; $22: 333-48$

3. Jacquier A, Dujon B. An intron encoded protein is active in a gene conversion process that spreads an intron into a mitochondrial gene. Cell I985; $4: 383-94$

$\mathrm{m} / \mathrm{s} n^{\circ} 7$, vol. 2, septembre is

\title{
Le clonage du facteur VII
}

Les facteurs de la coagulation sont clonés un à un. Après les facteurs antihémophiliques $A$ et $B$, c'est le tour du Facteur VII, pour lequel un ADN complémentaire a été obtenu par une équipe de Seattle [I]. Le facteur contient une séquence signal qui, une fois coupée, livre une chaîne de 406 acides aminés dont la séquence a été déduite de celle de l'ADNc. L'intérêt du clonage est d'abord de mieux comprendre le mécanisme d'activation du facteur VII : celui-ci est en effet transformé en facteur VII a activé par une simple coupure, donnant deux chaînes que maintient réunies un pont disulfure. C'est la chaîne lourde qui porte le site catalytique de cette protéase à sérine, alors que la chaîne légère contient la dizaine de résidus d'acide $\gamma$ carboxyglutamique qui caractérisent cette protéine vitamine $K$ dépendante. La séquence clonée a permis de placer exactement la coupure, entre une arginine et une isoleucine, et de fixer les dimensions des chaînes, respectivement de 254 et 152 acides aminés.

Le déficit en facteur VII est rare (de l'ordre de un cas sur un million) et ne justifie pas en soi la préparation de la protéine par génie génétique. Son obtention, possible dans un des systèmes développés pour la biosynthèse des protéines dépendantes de la vitamine $K$ (voir médecine/science $\mathrm{n}^{\circ} 6$, vol. I, p. 330) pourrait cependant s'avérer utile pour traiter des hémophiles porteurs d'anticorps antifacteur VIII [2]. Le facteur VII pourrait en effet, par le biais de la voie extrinsèque de la coagulation, court-circuiter le facteur VIII s'il est présent en quantité suffisante.

J.-C. D.

I. Hagen FS, Gray CL, O'Hara P, et al. Characterization of a cDNA coding for human factor VII. Proc Natl Acad Sci USA 1986; $83: 2412-6$. 2. Hedner U, Kisiel W. Use of human factor VII $a$ in the treatment of two hemophilia A patients with hight-titer inhibitors. $7 \mathrm{Clin}$ Invest 1983; $71: 1836-41$.

\section{Une sonde $A D N c$ spécifique du virus de l'hépatite $D$}

L'hépatite $D$ est une maladie souvent redoutable, observée chez des malades porteurs du virus de l'hépatite B [I]; elle est due à un virus, le virus de l'hépatite $\mathrm{D}$ (VHD) ou agent delta, incapable de se répliquer dans la cellule en l'absence du virus $B$, qui est co-infectant $[1,2$, 3]. L'enveloppe du virus $B$ (qui porte l'antigène $\mathrm{HBs}$ ) sert d'enveloppe au virus $D$. La génome du virus $D$ est constitué d'une molécule simple brin d'ARN. Afin d'obtenir une sonde pour la détection du virus $D$, l'ARN viral a été recopié en $\mathrm{ADN}$ complémentaire (ADNc) par la transcriptase reverse [4]; la copie ADNc a ensuite été insérée dans un plasmide permettant son amplification. Le clone recombinant obtenu permet de disposer à volonté d'une sonde ADNc. Celle-ci a été utilisée pour détecter le virus dans le sérum de malades infectés. Il suffit de I $\mu$ l de sérum pour obtenir, en hybridation moléculaire sur filtre (voir médecine/sciences $n^{\circ} 2$, vol. 2, p. 104), un bon signal chez un malade à la phase aiguë de l'infection, $0,5 \mathrm{ml}$ étant indispensable pour donner un signal équivalent chez un malade ayant une hépatite chronique [4]. L'ADNc obtenu jusqu'à présent est de petite taille ( 166 bases) et ne représente que moins du dixième du génome viral (environ 2000 bases). Son isolement constitue néanmoins un premier pas vers la caractérisation totale du génome. La sonde disponible a déjà un intérêt considérable pour le diagnostic et la compréhension de la maladie.

S.E.

I. Erlinger S. L'hćpatite D. médecine-sciences 1985; $1: 64-5$.

2. Bréchot C. L'agent delta : biologie et pathobiologic. médecine-sciences $1985 ;$ i : 66-8.

3. Bernuau J. Les hépatites dues au virus $D$. médecine-sciences $1985 ; \mathrm{I}: 69-73$

4. Denniston K J, Hoyer B H, Smedile A, Wells F V, Nelson J, Gerin J L. Cloned fragment of the hepatitis delta virus RNA genome: sequence and diagnostic application. Science $1986 ; 232: 873-5$. 